\title{
EXPERIMENTAL INVESTIGATION OF CRITICAL HEAT FLUX IN ANNULUS AT LOW PRESSURE AND LOW FLOW PARAMETERS
}

\author{
Daniel Vlček ${ }^{a, *}$, Ladislav SuK $^{c}, \mathrm{Kamil} \mathrm{ŠTevanka}^{b}$, Taron Petrosyan $^{b}$ \\ ${ }^{a}$ Czech Technical University in Prague, Faculty of Nuclear Sciences and Physical Engineering, Department of \\ Nuclear Reactors, Břehová 78/7, Prague, Czech republic \\ ${ }^{b}$ Brno University of Technology, Faculty of Electrical Engineering and Communication, Technická 10, 61600 \\ Brno, Czech Republic \\ ${ }^{c}$ Brno University of Technology, Faculty of Mechanical Engineering, Technická 2896/2, 61669 Brno, Czech \\ Republic \\ * corresponding author: daniel.vlcek1@gmail.com
}

\begin{abstract}
Steady state flow boiling experiments were conducted on a technically smooth Inconel 625 tube with outer diameter $9.1 \mathrm{~mm}$ at inlet pressures 131, 220 and $323 \mathrm{kPa}$, inlet temperatures 62 , 78 and $94{ }^{\circ} \mathrm{C}$ and approximately 400,600 and $1000 \mathrm{~kg} /\left(\mathrm{m}^{2} . \mathrm{s}\right)$ mass flow. Water of these parameters was entering into the vertically aligned annulus, where the uniformly heated tube was placed until the critical heat flux (CHF) appeared. The experimental data were compared to estimations of CHF by local PGT tube correlation and Groeneveld's look-up tables for tubes. The results imply that in the region of low pressure and low mass flux, the differences between calculations and experiments are substantial (more than $50 \%$ of CHF). The calculations further imply that look-up tables and tube correlations should be corrected to the annulus geometry. Here, the Doerffer's approach was chosen and led to a substantial enhancement of CHF estimation. Yet, a new correlation for the region of low pressure and flow is needed.
\end{abstract}

KEYWORDS: Correlations, critical heat flux, flow boiling, heat transfer, nuclear fuel cladding.

\section{INTRODUCTION}

Current trend in cladding materials of nuclear fuel is an accident tolerant fuel which is designated to replace the current zirconium-based alloy. There are several candidates for ATF cladding material with different benefits and drawbacks. To choose the best material, an extensive experimental testing has been conducted, however, a heat transfer characteristics of these materials are still an active research topic of interest. Towards making the ATF cladding material heat transfer analysis, the experimental facility with a primary database of different materials is needed.

Heat transfer characteristics of cladding material focuses mainly on cooling the heated fuel tubes and since the fuel is cooled mostly by water, a thermohydraulic analysis needs to be done. In this analysis, the key factor is the critical heat flux (CHF) phenomena which lead to a fast reduction of heat transfer coefficient with a steep rise of cladding temperature which can induce the rupture of the heated material. Better understanding of the boiling process is important for new fuel design and crucial for nuclear power plant safety analyses.

The boiling process can be separated in two groups by the flow of coolant. The first group is pool boiling, which is characterised by the natural circulation of the coolant. The experimental facilities can be usually easily maintained and therefore they have been carried out on lots of different materials. The results of pool boiling experiments show strong agreement on the impact of surface morphology on CHF [1, 2, 3, 4, The flow boiling experiment traditionally considers pressure, mass flow and inlet subcooling as major factors assuming that the impact of the material is limited [5]. Most of the flow boiling experiments were carried out in tube or in rod bundles at normal operating conditions of nuclear reactors, i.e., high pressure and high flow rate and therefore there is a lack of flow boiling data in the area of low flow and low pressure. After the Fukushima accident, the severe fuel damage conditions of reactors and fuel behaviour during them became one of the main research issues, therefore there is an interest in the low flow and low pressure parameters.

For the safety analysis, the CHF is usually predicted by a subchannel code. Its deterministic approach is based on a large experimental database from which the correlations were created. However, in the region of low flow and low pressure, the precision of the correlations is worse if not completely off. Most of the data were collected from tube experiments made from steel and zirconium. This has to be taken in mind because even the change of the geometry from tube to annulus can lead to significant changes of the predicted CHF. One way how to take account of bundle-specific effects (e. g., element gap size and curvature) together with the effects of low flow and low pressure is using specific correlations designed for annular geometry. The other way can be using the 


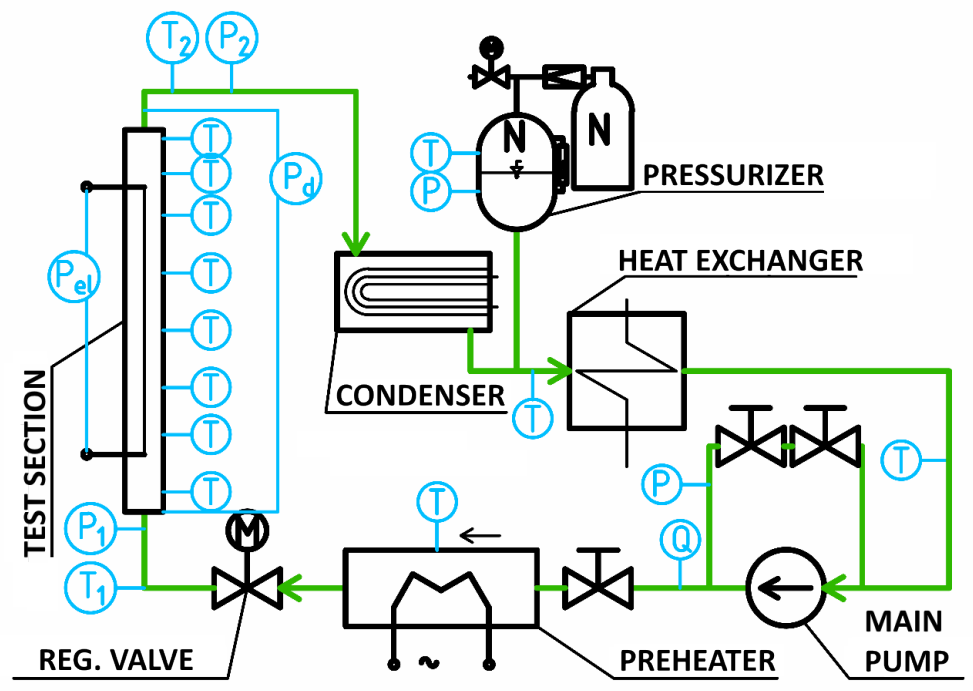

Figure 1. Process flow diagram of MRCHA test facility.

correcting factors on existing correlations.

Haas 6 summarised the experimental results from the available literature of flow boiling at low flow and low pressure in annular geometry. Rogers [7] and ElGenk [8] investigated CHF for water in an annulus in the problematic region mentioned above. Both of them developed separate empirical correlations which can unfortunately be used only in the small parameter range of their experimental data. Rogers also compared four different empirical correlations (Knoebel 9, McAdams [10, Menegus [11 and Katto [12 and all of them significantly overpredicted the experimental CHF in the annulus. Chun 13 compared their CHF experiments with Bowring [14, Doerffer [15] and Janssen and Kervinen [16] correlation. The Bowring correlation showed the best agreement with Chun's data, however all used correlations at lower pressures than $10 \mathrm{MPa}$ tended to overestimate CHF. Several correlations were studied at KAIST [17 and the equations from Doerffer [15] were suggested with caution for very low flow and pressure even though it was designated for pressures over $1 \mathrm{MPa}$. It can also be used for CHF look-up tables by Groeneveld [18 to correct $\mathrm{CHF}$ data from tube to annulus geometry. This approach led to the best result in Haas's research 6 . Mayer et al. 19] also presented the CHF results of annular flow at the pressure range from 110 to 225 $\mathrm{kPa}$ with changing mass flux and with comparison of their data with several correlations.

Except the literature comparison, Haas [20, 6] also presented his experimental data from the COSMOS-L experimental loop. This was the main inspiration for the author's research team to develop a test facility of similar design [21. Haas pointed out that flow boiling experiments could be strongly affected by instability, which could lead to pulsating flow and therefore these oscillations could cause a premature $\mathrm{CHF}$ at much lower heat fluxes.

Apart from the material structure, there are a lot of different effects that bias the CHF. The effect of clad thickness was discussed in [5] and for specific materials (Inconel 600 and SS316) it showed the decrease of CHF with increasing clad thickness up to $0.711 \mathrm{~mm}$. Lee 22, 23] also demonstrated that roughness and wettability have no clear impact on flow boiling CHF. These results were not in accordance with the pool boiling experiments.

The main object of this work was to measure a set of experiments on a technically smooth Inconel 625 tube. To achieve the least amount of instability, three different values of pressure, inlet subcooling and mass flux were chosen. Experimental data were compared to local CHF correlation PGT and Groeneveld's lookup tables. The Doerffer's approach was then used to improve the tube equations for the annulus model.

\section{EXPERIMENTAL SETUP}

The flow boiling experiments were performed on the Mobile Research Critical Heat Flux Apparatus (MRCHA) which was constructed and operated by the University of Technology in Brno at Faculty of Electrical Engineering and Communication and its thorough description can be found in the article [21].

The flow boiling test loop is formed by two circuits. The primary circuit delivers the deionized water (with conductivity circa $30 \mu \mathrm{S} / \mathrm{cm}$ ) to the test section under the desired conditions. The secondary circuit serves mainly as a heat exchanger between the primary circuit and the water mains, thus consisting of heat exchangers, a circulation pump and several bypasses. The primary circuit is more complex and connects the two circuits through a heat exchanger and condenser as can be seen in Fig. 1 .

The pressurizer stores the working fluid and separates the heated liquid and vapour coming out from the test section under the desired pressure. Heat exchanger cools down the heated water mainly from the condenser while the pressurizer is preheated to a 


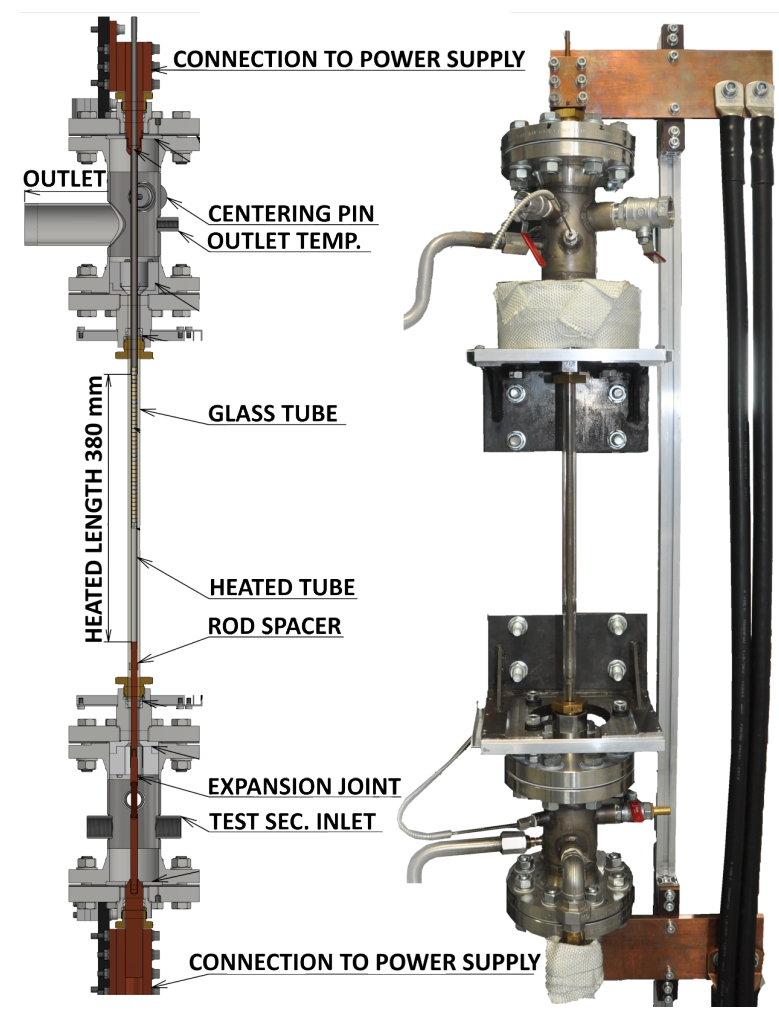

Figure 2. The cross-sectional view of the MRCHA test section with its actual view.

certain temperature to compensate for temperature differences. The main circulation pump then delivers the cooled water from the heat exchanger to the preheater, where the inlet temperature is set. To adjust the flow rate, a regulation valve is used directly behind the preheater. The water of the desired parameters enters the vertically aligned test section where it is uniformly heated by the electric current. At the outlet of the test section, a backflow valve is used to ensure the safety of the facility.

\subsection{Test SECTION}

The main part of the flow boiling test facility is a test section which is designed as a vertical annulus. A detailed cross-section of the test section next to its actual photo is shown in Fig. 2 The first experimental data were obtained on a $380 \mathrm{~mm}$ long uniformly heated Inconel 625 tube. The fluid enters the bottom part by two throats and goes through an unheated stability section, where the inlet temperature is measured.

The power from the power supply to the heated tube is delivered through the copper power terminals, which are designed as a $133 \mathrm{~mm}$ long rod with an outer diameter of $9 \mathrm{~mm}$ at the inlet section and a similar copper rod with the length of $113 \mathrm{~mm}$ and outer diameter of $10 \mathrm{~mm}$ at the outlet. Nickel is used to cover the copper conductors. Inside of the heated tube, a measurement probe is placed. To prevent water leakage from the test section to the test probe, the test tube and copper terminals are pressed together and then soldered with lead-free tin solder.
Since the temperature of the heated tube can reach more than $400^{\circ}$ the bottom copper terminal includes a thermal expansion joint to compensate for possible thermal dilatation.

The annular geometry of the test section is characterised in the Tab. 1. To ensure the centred position of the test tube in the glass surroundings, a spacer is placed in the lower part of the test section and a centring pin is located in the upper part. With the glass tube it is possible to closely observe ongoing phenomena by capturing the flow by a high speed camera. The only drawback can be the heat loss of it, however it was estimated to $50 \mathrm{~W}$ at the input power of $20 \mathrm{~kW}$.

\begin{tabular}{lr}
\hline Parameter & Value \\
\hline Outer diameter $\mathrm{d}_{o}[\mathrm{~mm}]$ & 14.5 \\
Inner diameter $\mathrm{d}_{i}[\mathrm{~mm}]$ & 9.1 \\
Gap width $\delta[\mathrm{mm}]$ & 2.7 \\
Heated length $[\mathrm{mm}]$ & 380 \\
Wetted perimeter $[\mathrm{mm}]$ & 74.1 \\
Heated perimeter $[\mathrm{mm}]$ & 28.6 \\
Length to heated eq. diameter $[\mathrm{mm}]$ & 27.1 \\
Length to hydraulic diameter $[\mathrm{mm}]$ & 70.4 \\
Length to inner diameter $[\mathrm{mm}]$ & 41.8 \\
\hline
\end{tabular}

TABLE 1. The details of test annulus geometry.

The test section is heated by the direct current power supply via copper power terminals. Active power of the supply is $120 \mathrm{~kW}$ and it can steadily provide $1000 \mathrm{~A}$ and $100 \mathrm{~V}$ and it can burst up to 1700 $\mathrm{A}$ and $70 \mathrm{~V}$ for a desired length of the heated test tube.

The temperature of the test tube is measured by nine K-type thermocouples with a sheet diameter of $0.5 \mathrm{~mm}$ installed on the inner surface of the heated length as a test probe. More precise measurement of the flow temperature is needed, so two 4-wire platinum PT100 sensors are installed at the inlet and outlet of the test section.

The test probe was upgraded several times. The first version was a copy of Haas's design [6] and was created from steel components isolated with small plastic rings from PEEK material, see the first two parts of Fig. 3 Unfortunately, the first version was not working, so a new version was made. The second version was constructed completely from PEEK material with perfect isolation of thermocouples but weak temperature stability. It was not ideal for higher inlet temperatures, therefore it was not ideal for longterm use. Finally, the third version of the test probe was made. The whole probe was created from ceramic rings. The last version of the probe can last high temperatures and it is completely nonconducting. The main purpose of the probe remained the same throughout the all versions - to pin the thermocouples down to the test tube so that the temperature could be measured. The thermocouples were inserted in the 

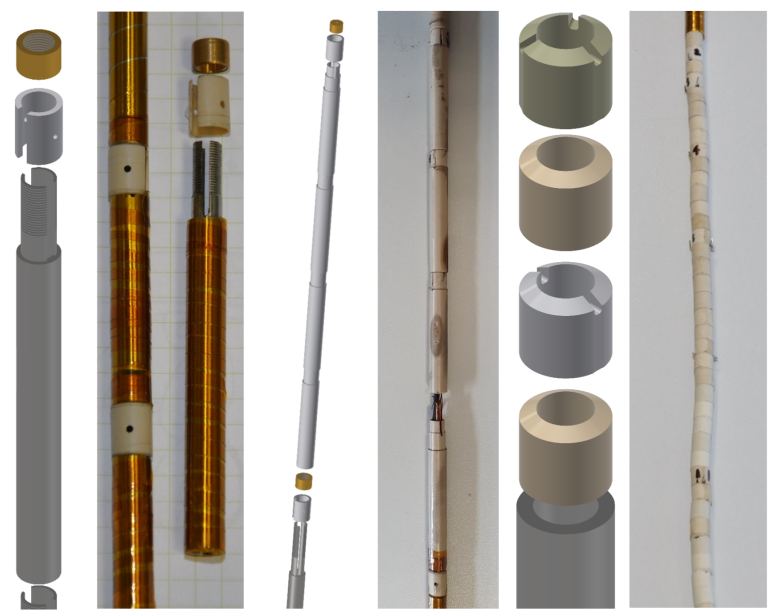

Figure 3. From left to the top is a design and its actual photography of the first, the second and the third version of measurement probe.

probe at different axial positions from top to bottom at $10,60,110,160$ and $210 \mathrm{~mm}$. The thermocouples were doubled at the four top positions to better register the onset of boiling crisis. Most of the data in this paper were collected with the second version.

\subsection{Measurement procedure and UNCERTAINTIES}

Prior to the CHF measurements, the degassing of the test loop had to be done. The process usually took about 20 minutes when the water had boiled until the oxygen content in the loop reached the value of circa $0.8 \mathrm{mg} / \mathrm{L}$. After this, the loop was ready to use and the parameters were adjusted to the desired values and the power could be slowly increased until the CHF was detected. Before the beginning of the experimental work, the flow regimes had to be set. The selection of the inlet parameters was made on the basis of previous experience to achieve the least amount of instability and can be seen in Tab. 2 The parameters were then kept constant while the power input was increased by $350 \mathrm{~W} / \mathrm{min}$.

\begin{tabular}{lrrrr}
\hline Parameter & & Average & Std. d. & Rel. d. \\
\hline Mass flux & $\mathrm{G}_{1}$ & 407.7 & 12.4 & $3.0 \%$ \\
$G\left[\mathrm{~kg} /\left(\mathrm{m}^{2} . \mathrm{s}\right)\right]$ & $\mathrm{G}_{2}$ & 594.3 & 28.1 & $4.7 \%$ \\
& $\mathrm{G}_{3}$ & 1024.1 & 5.6 & $0.5 \%$ \\
Temperature & $\mathrm{T}_{1}$ & 61.5 & 1.6 & $2.6 \%$ \\
$T_{\text {in }}\left[{ }^{\circ} \mathrm{C}\right]$ & $\mathrm{T}_{2}$ & 78.2 & 3.2 & $4.0 \%$ \\
& $\mathrm{~T}_{3}$ & 93.6 & 1.0 & $1.1 \%$ \\
Pressure & $\mathrm{P}_{1}$ & 130.5 & 5.1 & $3.9 \%$ \\
$p_{\text {in }}[\mathrm{kPa}]$ & $\mathrm{P}_{2}$ & 220.4 & 12.2 & $5.5 \%$ \\
& $\mathrm{P}_{3}$ & 323.0 & 14.7 & $4.5 \%$ \\
\hline
\end{tabular}

TABLE 2. Experimental setup of parameters with deviations from 21 runs on smooth Inconel 625 tube.

During the power ramping, the temperatures of the $\mathrm{K}$-type thermocouples in the test probe were closely watched and when the temperature limit was crossed, the input power was automatically shut off. Ideally, during every temperature overshoot, the critical heat flux appeared and its location was registered. Every experimental run took usually about 30 minutes.

Different measurement devices were installed in the test facility to control and adjust the flow parameters. Mass flux was measured by Coriolis flow meter Promass 80F15, inlet fluid temperature was measured by PT100 sensors. Pressure was captured with BD SENSORS DMP 331i. The output from the power source was measured by a shunt resistor. The devices were checked in calibration tests and the accuracy of every measured parameter is stated in the Tab. 3 The accuracy of the test section thermocouples is also stated, but their precision was not crucial for $\mathrm{CHF}$ detection.

\begin{tabular}{lrr}
\hline Measured value & Range & Accuracy \\
\hline Pressure $[\mathrm{kPa}]$ & $100-300$ & $1.07 \%$ \\
Temp. inlet $\left[{ }^{\circ} \mathrm{C}\right]$ & $64-93$ & $0.3{ }^{\circ} \mathrm{C}$ \\
Temp. test section $\left[{ }^{\circ} \mathrm{C}\right]$ & up to 350 & $5{ }^{\circ} \mathrm{C}$ \\
Mass flow $\left[\mathrm{kg} \cdot \mathrm{h}^{-1}\right]$ & $152-229$ & $0.33 \%$ \\
Mass flux $\left[\mathrm{kg} \cdot \mathrm{m}^{-2} \cdot \mathrm{s}^{-1}\right]$ & $400-600$ & $3.22 \%$ \\
Power $[\mathrm{kW}]$ & 30 & $0.67 \%$ \\
Heat flux $\left[\mathrm{kW} \cdot \mathrm{m}^{-2}\right]$ & $1050-2650$ & $3.5 \%$ \\
\hline
\end{tabular}

TABle 3. Accuracy of measurement devices

According to 21 the power is calculated by the multiplication of electric current and voltage. The heat flux is then estimated by dividing the power by the heated surface which is equal to $\pi \cdot d_{i} \cdot L$, where $d_{i}$ is the inner diameter of the annulus and $L$ is the heated length. The relative deviation is calculated as:

$$
\frac{\Delta q}{q}=\frac{\Delta Q}{Q}+\frac{\Delta d_{i}}{d_{i}}+\frac{\Delta L}{L} .
$$

The mass flux was calculated by dividing the measured mass flow rate $\mathrm{F}$ by the flow area of the annulus and the relative deviation was determined as:

$$
\frac{\Delta G}{G}=\frac{\Delta F}{F}+\frac{2 \cdot d_{o} \Delta d_{o}}{d_{o}^{2}-d_{i}^{2}}+\frac{2 \cdot d_{i} \Delta d_{i}}{d_{o}^{2}-d_{i}^{2}} .
$$

All calculated relative deviations together with the accuracy of the measured parameters can be seen in Tab. 3

\section{Results And Discussion}

The steady state critical heat flux experiments were measured on several surfaces, but in this paper the first experiments on Inconel 625 tube were chosen for comparison with calculations.

The test parameters are summed up in the Tab. 2 The values of mass flux, temperature and pressure were at first set to the desired values (to prevent oscillations) and then the results were averaged and the deviations were calculated. The summarized graphs 


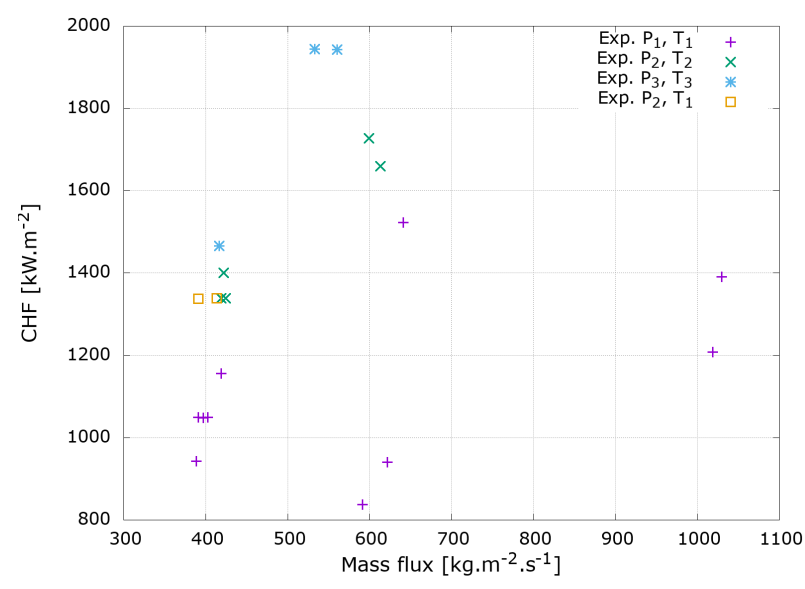

Figure 4. CHF against inlet mass flux with different inlet pressure and temperature according to Tab. 2

and their comparison to literature experimental measurements are the first part of validation of the test facility. The overall results are comparable to Haas's [6], El-Genks's [8] and Roger's [7] data.

The constant input parameters were kept as steady as possible, however, as the CHF was close, the pressure started to oscillate. Moreover, the first experiments were affected by a certain lack of experience and it led to a larger deviation from the input parameters than expected, see Tab. 2, The deviations could be avoided by creating separate points of inlet pressure, temperature and mass flux, however this approach was chosen only in Figs. 4, 5 and 6 where different effects on CHF were captured. The Figs. 7, 8, 9 and 10 show the comparison between experimental values and calculations and in these figures the average value of CHF was used together with deviations from Tab. 2

In essence, three sets of pressure, temperature and mass flux were conducted to achieve and measure the reproducibility of the experiments. The result can be seen that CHF strongly depends on even small changes of these parameters and therefore it is crucial to stabilize them as much as possible. The trends in increasing the values of the parameters can be seen, however more measurements have to be done to lower the deviations and fill the blank spaces between regimes.

\subsection{EFFECT OF FLOW PARAMETERS}

The data were at first analyzed according to the effects of increasing inlet pressure, mass flux and temperature. The CHF behaved as expected and in agreement with El-Genk et al. [8], Mayer et al. [19] and Haas et al. [6] who also captured the effects of flow parameters on CHF. In the Fig. 4 it can be seen that with rising mass flux the CHF values also grow. The mass flux function was also chosen for calculation comparison and the effect can be also seen.

The two values of midrange mass flux were unfortunately lower against the desired value, so the mass

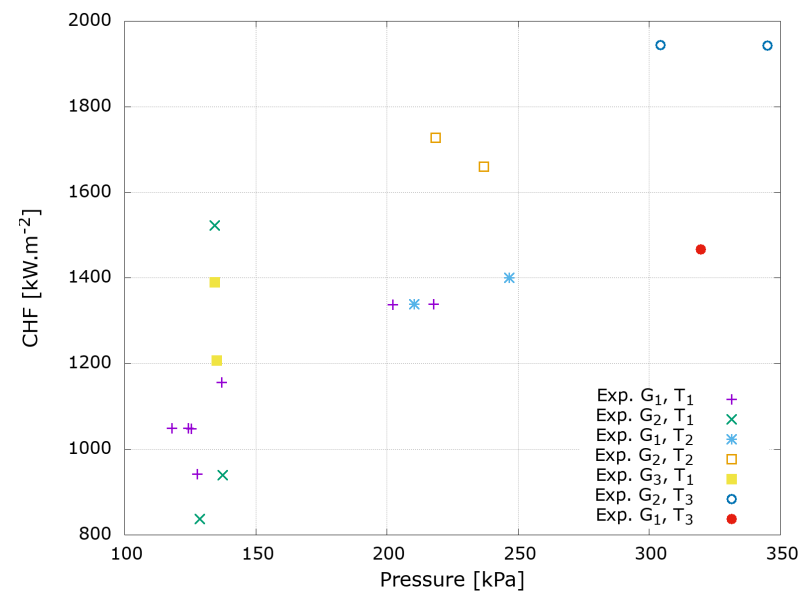

FigURE 5. CHF against inlet pressure with different inlet mass flux and temperature according to Tab. 2

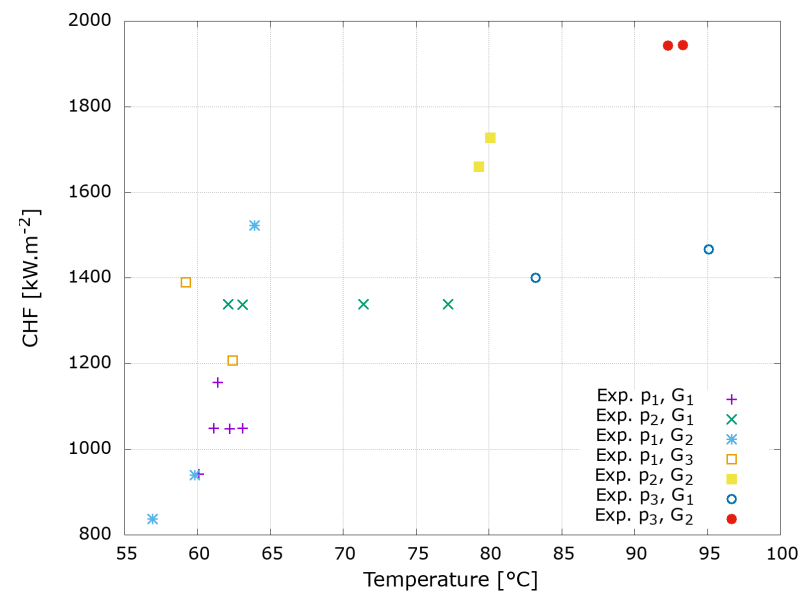

Figure 6. CHF against inlet temperature with different inlet pressure and mass flux according to Tab. 2

flux deviation in Tab. 2 is considerably high. It was caused by the lack of experience in the early experiments and during these experimental runs the amount of instability was extensive. Therefore, for the next analysis, the data were filtered with the number characterizing the amount of instability (the overall view on behavior of the loop).

The experiments were then plotted against inlet pressure, see Fig. 5. The pressure has an impact on the density, viscosity, surface tension, and finally the boiling temperature of the fluid. The rising of $\mathrm{CHF}$ is also in agreement with theoretical assumptions and with the literature as, for example, Chun et al. [13.

It can be seen that the pressure varies a lot around its desired value. Better results of maintaining the pressure were at lower values, however the small amount of data at higher pressures and worse stabilization led to pressure deviations up to $5.5 \%$, as can be seen in Tab. 2 The main outcome of the pressure effect was that the pressure has to be measured at the outlet of the test section because it is more stable and not violated by the instability. Here the inlet 


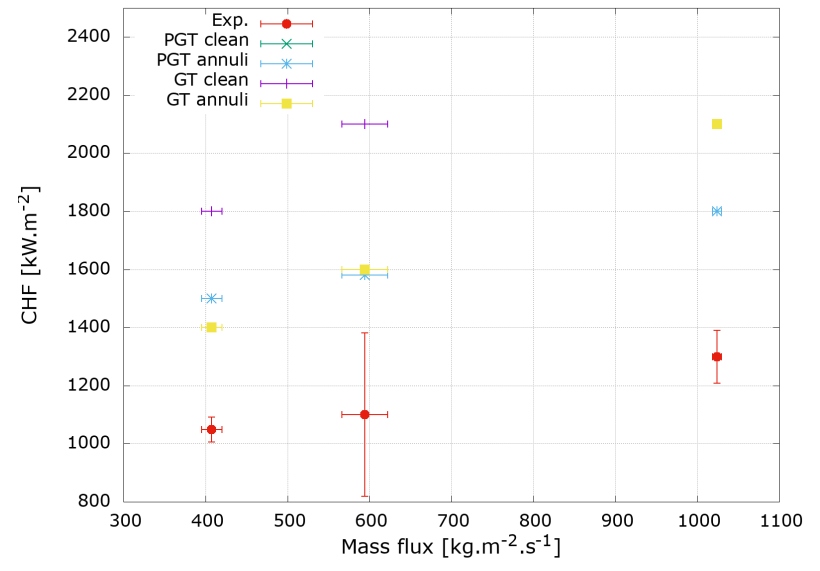

Figure 7. Comparison of CHF results against calculations with PGT correlation and Groeneveld's tables at $p_{i n}=131 \mathrm{kPa}$ and $T_{i n}=62{ }^{\circ} \mathrm{C}$.

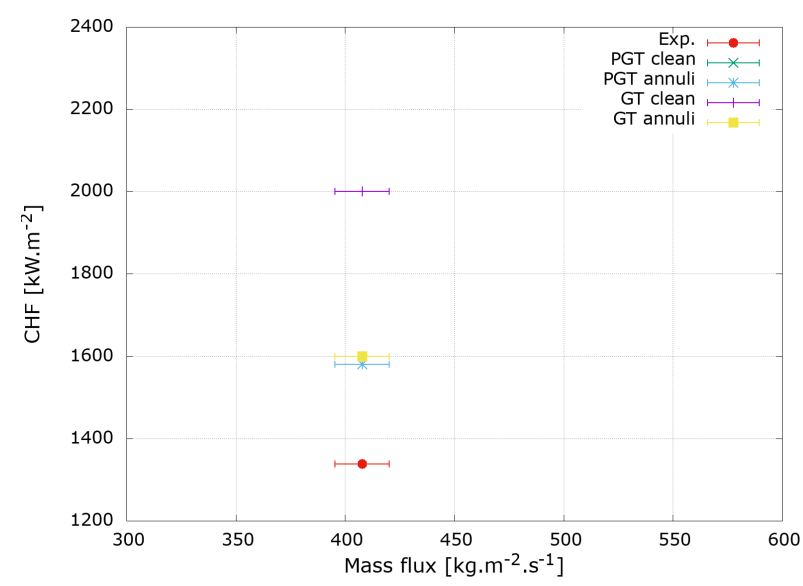

Figure 8. Comparison of CHF results against calculations with PGT correlation and Groeneveld's tables at $p_{\text {in }}=220 \mathrm{kPa}$ and $T_{i n}=62{ }^{\circ} \mathrm{C}$.

values were chosen to use them in the calculations. For the next analysis, the computations should be set to the outlet pressure.

The last total comparison illustrates the effect of inlet temperature to CHF. Again, the rising dependency of its increasing value can be seen in Fig. 6 . In the figure there can be seen a strong variation of the midrange inlet temperature, however, because of small values of temperature the deviation is still quite small. Inlet temperature was set together with pressure and the two parameters created three sets except the experimental setup with lower inlet temperature and higher pressure. That means that the effect of these two parameters on CHF was almost the same.

\subsection{Calculations}

Since the tube or annulus geometry prevents the uprising of cross-flow, the use of complex subchannel codes is redundant. The local FNSPE simple code TUBE 2.0 [24], which uses the method of isolated channel, was chosen.

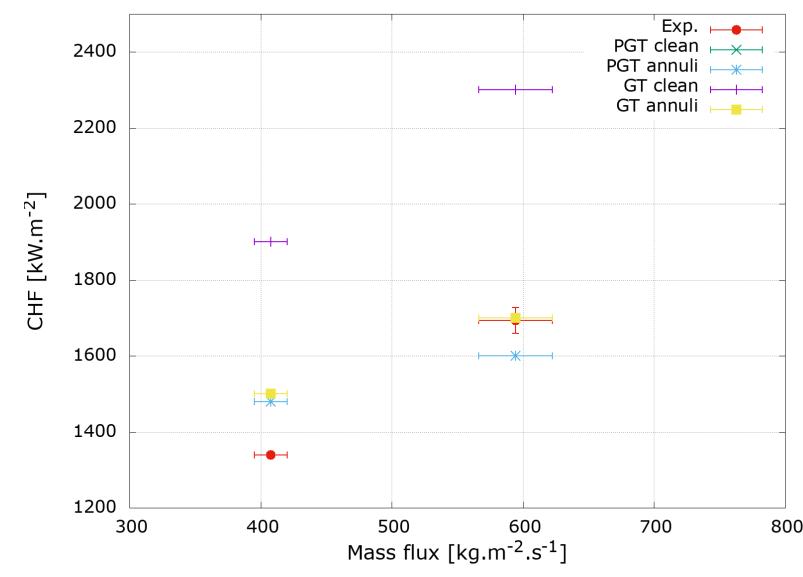

Figure 9. Comparison of CHF results against calculations with PGT correlation and Groeneveld's tables at $p_{\text {in }}=220 \mathrm{kPa}$ and $T_{i n}=78^{\circ} \mathrm{C}$.

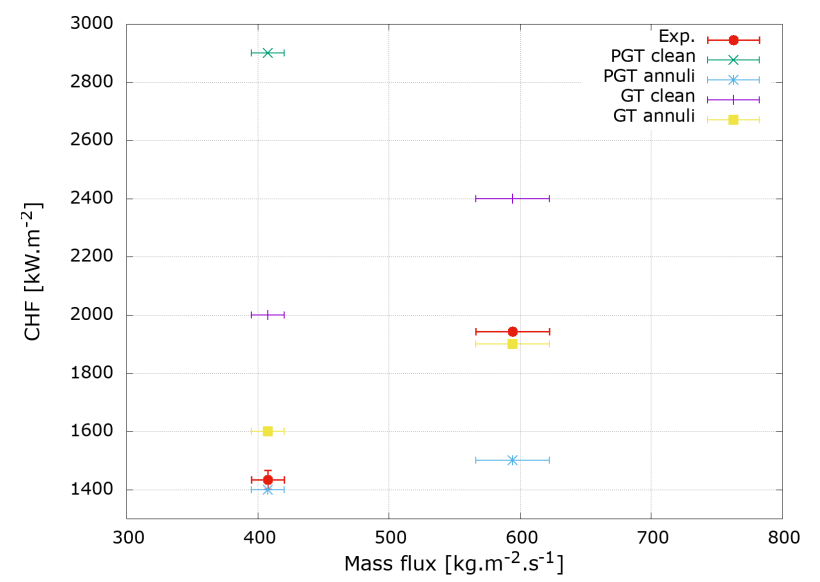

Figure 10. Comparison of CHF results against calculations with PGT correlation and Groeneveld's tables at $p_{\text {in }}=323 \mathrm{kPa}$ and $T_{i n}=94{ }^{\circ} \mathrm{C}$.

In this paper, the prediction of CHF was made using the average values stated in the Tab. 2 Two different approaches were tested against the experimental data. The first method (clean) included tube geometry correlation PGT [25] and Groeneveld's look-up tables [18] for CHF in tubes then Doerffer's [15] corrective correlation for annulus was used for either of them (annuli). Although the PGT correlation was designed for pressures greater than 0.3 $\mathrm{MPa}$, its functionality was tested beyond its validity range. The results of CHF were rounded to $100 \mathrm{~kW} / \mathrm{m}^{2}$ and because of quite large deviations from the average values of the inlet parameters of the pretests, the uncertainties of the calculations were not estimated. However, the overall view can be seen from the presented Figs. $7,10$.

The axis range was chosen approximately for $100 \%$ deviation from the experimental data and therefore some of the calculated data with very large deviation were not shown (PGT clean). The deviations from the inlet parameters and CHF (see Tab. 2) were also plotted in the figures. 
From the pictures, it can be seen that the tube results (PGT and GT clean) significantly vary (more than $50 \%$ ) from the experimental values and with Doerffer's correction the results were notably better (from 10 to $40 \%$ ). In some cases (see Fig. 9 and 10, the PGT correlation underestimated the CHF.

The look-up tables from Groeneveld with Doerffer's correction led to slightly better or the same results as PGT correlation with the correction because of the underpredicted CHF at $323 \mathrm{kPa}$ (see Fig. 10 but the PGT was closer to the highest mass flux in the Fig. 7.

The correction to annular geometry substantially improves the predictions of CHF, but at very low pressure there is still more than $35 \%$ overestimation and with rising pressure the value decreases to almost $10 \%$.

Mayer et al. 19] also compared their data with lookup tables and they had better results with the older version of Groeneveld's tables from 1995, and they used different correlations from El-Genk et al. [8] and it led to radical improvement of the CHF prediction. Haas et al. [6] used the correlation from Rogers [7] because the geometry of their test section was similar. Haas also used look-up tables from different years and he also corrected them with Doerffer's factors. He stated that all look-up tables tend to overestimate the $\mathrm{CHF}$ and the best results were gained from Rogers correlation. Here, the older versions of the tables were not used because Groeneveld stated that it is always updated from the older version. Doerffer [15] presented also a separate correlation but it showed inconsistent behaviour with Haas's data.

\section{Conclusion}

The flow boiling critical heat flux was measured on a uniformly heated Inconel 625 tube inserted in a vertically aligned annulus test section at various mass fluxes and pressures. The set of inlet parameters was initially selected to allow a direct and consistent comparison of the tested cladding. The measured results broaden the CHF database for Inconel 625 material at low pressure and low flow during which this particular material has never been tested. In addition, the comparison with the CHF correlations has never been done with the selection of Inconel 625 and inlet parameters stated above.

The main conclusions from the experiments on a technically smooth Inconel tube and the comparison with calculation methods are summarized here.

(1.) The CHF values showed an increasing tendency for pressures in the range from $131 \mathrm{kPa}$ to $323 \mathrm{kPa}$ for several measured mass flux values.

(2.) The CHF values also increased with rising mass flux, which was in accordance with the literature.

(3.) CHF was predicted using look-up tables and PGT correlation both in its original tube form and corrected to annular geometry. The geometry correction made a substantial improvement of the pre- diction, however the correlation together with the tables still tend to overestimate the CHF. The results of the two corrected methods were similar.

(4.) For very low pressure $(131 \mathrm{kPa})$, the corrected methods are about $40 \%$ higher and the deviation decreases with increasing pressure. For 220 and $323 \mathrm{kPa}$, it is only about $10-15 \%$ higher than the experimental values.

In the future, more flow boiling experiments should be performed to better support the observed findings. Presented data should serve as a reference for comparison with other materials including accident tolerant fuel [26]. The facility should be improved for ionex filters preventing the corrosive particles from depositing on test tubes and therefore extend the operation time with a clean surface as it was discussed in [21. To obtain better flow stability and less oscillations, the inlet section will be slightly modified together with the change of the measuring probe. These modifications should allow us to measure at higher mass fluxes. The effects of wettability, capillarity, porosity and roughness on $\mathrm{CHF}$ should be evaluated. The $\mathrm{CHF}$ analysis will be focused more on the surface characteristics of different materials and together with that a more thorough comparison of the measured data with the CHF correlations will be done. As for the calculation, other correlations should be used to find the most suitable one for this test section. Length to heated diameter ration should be put in mind when choosing the most suitable correlation. With more experimental data, a new correlation can be created or a new corrective factor can be developed.

\section{LIST OF SYMBOLS}

$d_{i}$ Inner diameter $[\mathrm{mm}]$

$d_{o}$ Outer diameter [mm]

$d_{h e}$ Heated equivalent diameter [mm]

$\delta \quad$ Gap width [mm]

$F \quad$ Flow rate $\left[\mathrm{kg} \mathrm{s}^{-1}\right]$

$G$ Mass flux $\left[\mathrm{kg} \mathrm{m}^{-2} \mathrm{~s}^{-1}\right]$

$\Delta h_{\text {in }}$ Inlet subcooling $\left[\mathrm{kJ} \mathrm{kg}^{-1}\right]$

$L$ Length [mm]

$p_{\text {in }}$ Inlet pressure $\left[\mathrm{K}^{-1}\right]$

$q$ Heat flux $\left[\mathrm{kW} \mathrm{m}^{-2}\right]$

$T_{\text {in }}$ Inlet temperature $\left[{ }^{\circ} \mathrm{C}\right]$

ATF Accident Tolerant Fuel

CHF Critical Heat Flux

COSMOS-L Critical-heat-flux On Smooth and Modified Surfaces - Low pressure loop

CTU Czech Technical University in Prague

KAIST Korea Advanced Institut for Science and Technology

MRCHA Mobile Research Critical Heat Flux Apparatus

\section{ACKNOWLEDGEMENTS}

The support from the Student grant contest from CTU in Prague with code SGS20/187/OHK4/3T/14 is gratefully acknowledged. Many thanks belong to my supervisor 
Ing. Dušan Kobylka, Ph.D and my consultant Ing. Martin Ševeček who provided insight and expertise that greatly assisted the research. Special thanks belong to Ing. Ladislav Suk and his team from Brno who made all experiments possible. I would also like to thank Ing. Vojtěch Caha for his constructive criticism and friendly advice during the project work.

\section{REFERENCES}

[1] G. H. Seo, G. Jeun, S. J. Kim. Enhanced pool boiling critical heat flux with a fecral layer fabricated by dc sputtering. International Journal of Heat and Mass Transfer 2016(vol. 102):1293-1307, 2016. DOI:10.1016/j.ijheatmasstransfer.2016.06.077

[2] H. H. Son, Y. S. Cho, S. J. Kim. Experimental study of saturated pool boiling heat transfer with fecral- and cr-layered vertical tubes under atmospheric pressure. International Journal of Heat and Mass Transfer 2019(vol. 128):418-430, 2019. DOI:10.1016/j.ijheatmasstransfer.2018.09.013

[3] A. F. Ali, J. P. Gorton, N. R. Brown, et al. Surface wettability and pool boiling critical heat flux of accident tolerant fuel cladding-fecral alloys. Nuclear Engineering and Design 2018(vol. 338):218-231, 2018. DOI:10.1016/j.nucengdes.2018.08.024

[4] D. H. Kam, J. H. Lee, T. Lee, Y. H. Jeong. Critical heat flux for sic- and cr-coated plates under atmospheric condition. Annals of Nuclear Energy 2015(vol. 76):335-342, 2015. DOI:10.1016/j.anucene.2014.09.046

[5] S. K. Lee, M. Liu, N. R. Brown, et al. Effect of heater material and thickness on the steady-state flow boiling critical heat flux. Nuclear Technology 206(2):339-346, 2020-02-01. DOI:10.1080/00295450.2019.1670010.

[6] C. Haas, T. Schulenberg, T. Wetzel. Critical heat flux for flow boiling of water at low pressure in vertical internally heated annuli. International Journal of Heat and Mass Transfer 2013(vol. 60):380-391, 2013. DOI:10.1016/j.ijheatmasstransfer.2012.12.038

[7] J. T. Rogers, M. E. Salcudean, A. E. E. Tahir. Flow boiling critical heat fluxes for water in a vertical annulus at low pressure and velocities. Proceeding of International Heat Transfer Conference 7 1982:339-344, 1982. DOI:10.1615/IHTC7.1180

[8] M. S. El-Genk, S. J. Haynes, K. Sung-Ho. Experimental studies of critical heat flux for low flow of water in vertical annuli at near atmospheric pressure. International Journal of Heat and Mass Transfer 31(11):2291-2304, 1988. DOI:10.1016/0017-9310(88)90161-5

[9] D. H. Knoebel, S. D. Harris, B. J. Crain, R. M. Biderman. Forced-convection subcooled critical heat flux. D2O and H2O coolant with aluminum and stainless steel heaters. INIS, USAEC, vol. 4 is. 19 edn., 1973.

[10] W. H. McAdams, W. E. Kennel, C. S. Minden, et al. Heat transfer at high rates to water with surface boiling. Industrial and Engineering Chemistry 41(9):1945-1953, 1949. DOI:10.1021/ie50477a027.

[11] R. L. Menegus. Burnout of Heating Surfaces in Water. Atomic Energy Division, Wilmington, Delaware, 1st edn., 1959.
[12] Y. Katto. Generalized correlations of critical heat flux for the forced convection boiling in vertical uniformly heated annuli. International Journal of Heat and Mass Transfer 22(4):575-584, 1979. DOI:10.1016/0017-9310(79)90061-9

[13] S.-Y. Chun, H.-J. Chung, S.-K. Moon, et al. Effect of pressure on critical heat flux in uniformly heated vertical annulus under low flow conditions. Nuclear Engineering and Design 203(2-3):159-174, 2001. DOI:10.1016/S0029-5493(00)00307-1

[14] R. Bowring. Heat and fluid flow in water reactor safety. Mechanical Engineering Publications for the Institution of Mechanical Engineers London, 1977.

[15] S. Doerffer, D. Groeneveld, S. Cheng, K. Rudzinski. A comparison of critical heat flux in tubes and annuli. Nuclear Engineering and Design 149(1-3):167-175, 1994. DOI:10.1016/0029-5493(94)90283-6.

[16] E. Janssen, J. Kervinen. The critical boiling heat flux at high flows and high qualities. General Electric, 1964.

[17] J.-W. Park, W.-P. Baek, S. H. Chang. Assessment of chf correlations for internally heated concentric annulus channels. International Communications in Heat and Mass Transfer 23(8):1077-1086, 1996. DOI:10.1016/S0735-1933(96)00089-9

[18] D. Groeneveld, J. Shan, A. Vasić, et al. The 2006 chf look-up table. Nuclear Engineering and Design 237(15-17):1909-1922, 2007. DOI:10.1016/j.nucengdes.2007.02.014.

[19] G. Mayer, R. Nagy, I. Nagy. An experimental study on critical heat flux in vertical annulus under low flow and low pressure conditions. Nuclear Engineering and Design 310:461-469, 2016. DOI:10.1016/j.nucengdes.2016.10.026.

[20] C. Haas, L. Meyer, T. Schulenberg. Flow instability and critical heat flux for flow boiling of water in a vertical annulus at low pressure. ASME/JSME 2011 8th Thermal Engineering Joint Conference 2011:11, 2011-03-13. DOI:10.1115/AJTEC2011-44292

[21] L. Suk, T. Petrosyan, K. Stevanka, et al. Experimental investigation of critical heat flux on different surfaces at low pressure and low flow. Energies 13:5205, 2020. DOI:https://doi.org/10.3390/en13195205.

[22] S. K. Lee, M. Liu, N. R. Brown, et al. Comparison of steady and transient flow boiling critical heat flux for fecral accident tolerant fuel cladding alloy, zircaloy, and inconel. International Journal of Heat and Mass Transfer 2019(vol. 132):643-654, 2019. DOI:10.1016/j.ijheatmasstransfer.2018.11.141.

[23] S. K. Lee, Y. Lee, N. R. Brown, et al. Elucidating the impact of flow on material-sensitive critical heat flux and boiling heat transfer coefficients. International Journal of Heat and Mass Transfer 158:643-654, 2020. DOI:10.1016/j.ijheatmasstransfer.2020.119970.

[24] V. Caha, D. Vlcek. TUBE 2.0-PostCHF Users guide. DNR FNSPE CTU in Prague, Prague, 2017.

[25] R. Pernica, J. Cizek. General correlation for prediction of critical heat flux ratio in water cooled channels. In Proceedings of the 7th International Topical Meeting On Reactor Thermal Hydraulics, vol. Vol. IV, pp. 2636-2653. Saratoga Springs, New York, 1995. 
[26] Accident Tolerant Fuel Concepts for Light Water Reactors. No. 1797 in TECDOC Series. IAEA, Vienna, 2016. 